\title{
pÿThe Experience of Laboratory Learning How Do Chemistry Students Perceive Their Learning Environment?
}

\section{Sandström, Niclas}

2014-11

pÿSandström , N , Ketonen , E \& Lonka , K 2014 , ' The Experience of Laboratory Learning How Do Chemistry Students Perceive Their Learning Environment? ' , The European Journal of Social \& Behavioural Sciences, vol. 11 , no. 4 , pp. 1612-1625 . https://doi.org/10.15405/ejsbs.144

http://hdl.handle.net/10138/232970

https://doi.org/10.15405/ejsbs.144

cc_by_nc_nd

publishedVersion

Downloaded from Helda, University of Helsinki institutional repository.

This is an electronic reprint of the original article.

This reprint may differ from the original in pagination and typographic detail.

Please cite the original version. 


\title{
The European Journal of Social and Behavioural Sciences EJSBS
}

(eISSN: 2301-2218)

\section{The Experience of Laboratory Learning - How Do Chemistry Students Perceive Their Learning Environment?}

\author{
Niclas Sandström ${ }^{\mathrm{a}}$, Elina Ketonen ${ }^{\mathrm{b}} \&$ Kirsti Lonka \\ Corresponding Author: Niclas Sandström \\ ${ }^{a, b, c}$ Faculty of Behavioural Sciences, Department of Teacher Education \\ Visiting address: Siltavuorenpenger $5 \mathrm{~A}$ \\ P.B. 9 / 00014 University of Helsinki, Helsinki, Finland
}

http://dx.doi.org/10.15405/ejsbs.144

\begin{abstract}
Universities have in the recent years faced new challenges as the new generations of students enter the old institutions. We have to rethink both the physical facilities and the practices of higher education. Many of the incomers belong to the so-called digital natives who use various digital applications and mobile devices as integrated parts in their everyday lives. Their knowledge seeking and knowledge sharing activities are different from previous generations. This study stems from a need to acknowledge this gap in research on the changes in knowledge practices and their relationship to learning. The participants were university chemistry students, who were interviewed concerning their perceptions of the learning environments. The interviews revealed a variation in students' perceptions. There was also a variation in how they felt the physical tools provided affordances for their cognition. Some students needed much more external scaffolding and procedural facilitation for their laboratory work. The results are in line with previous research on the domainspecific features in sciences. In the future, the results are going to be looked at more in-depth in relation to students' epistemological beliefs.
\end{abstract}

C) 2014 Published by Future Academy www.FutureAcademy.org.uk

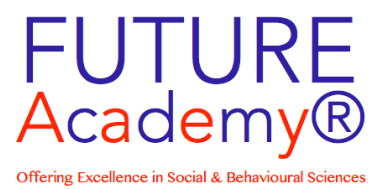

Open Access licence: (c) $\Theta \Theta \Theta$ (i)

http://dx.doi.org/ 


\section{Introduction}

Learning environments and learning organisations have in the recent years been faced with radical changes as new generations of students enter the old institutions. Both the physical facilities and the practices that the organizations entertain may be challenged (Faulkner \& McLaughlin, 2012; Harrison \& Hutton, 2014). Many of the newcomers belong to the socalled digital natives (Prensky, 2012) who use various digital applications and mobile devices as integrated parts in their everyday lives in different knowledge seeking and knowledge sharing activities. However, not much is known about the relationship between students' beliefs about knowledge - their epistemologies - and their perceptions of different learning environments.

Learning always takes place in a context: it is not only a process of acquiring more knowledge, but rather, increasingly active participation in a culture (Lave \& Wenger, 1991; Lonka, 2012). In higher education, as well, the ways students learn are embedded in the different dimension of the learning environment. This context is not only situational, but it relies on culturally and historically developed structures (Vygotsky, 1978). The cognitive development of human beings depends of on a certain kind of cultural environment for its realization (Tomasello, 1999).

Bruner (1996) pointed out the power of culture in shaping human mind. Also the environments where learning takes place shape our intellectual efforts. Our activities are mediated by varying tools and artifacts (Hakkarainen, 2009). The physically distributed cognition and intelligence is supported and emergent along with technological innovations (Hakkarainen et al., 2013). Today, also technologies and social media mediate our forms of collaboration and learning even though we may not at all times be aware of it. Even when we are not using such aids ourselves, they inevitably change the ways of communication in the society. For example, many societal movements and revolutions have spread and been reinforced by Twitter, and innovations - areally and intellectually - are spread and mediated by these technological prostheses that we use in the ordering of things and in communication (see also Hakkarainen et al., 2004).

Learning environments consist of the practices of teaching, learning, and assessment (Biggs, 1996) as well as the physical learning environment. Biggs (1996) used the concept constructive alignment to describe an ideal educational enterprise in which students adopt approaches to learning allowing for a profound understanding of the learning material, and in which all aspects of the teaching, including the assessment systems, are aligned to, and support these approaches.

Relationships between teaching and learning are not always simple. Rather, they are mediated by students' goals and strategies as well as situational factors. Lindblom-Ylänne \& Lonka (1999) investigated this dynamic interplay between learners and the learning environment in a traditional educational setting by using Vermunt \& Verloop's (1999) idea of frictions between learners and learning environment. A friction may be either constructive or destructive, the former promoting 
students' intellectual development, and the latter hindering it. Lindblom-Ylänne and Lonka (1999; 2001) found indications of destructive frictions when medical students, in their attempts to make sense of the learning environment and its requirements, were prone to adopting superficial learning strategies that were below their knowledge capacity. Their study showed that the best students of that time did not entertain very collaborative ideas of learning. Only later, Lonka et al. (2008) introduced the concept collaborative construction of knowledge, a perspective that had become a more common epistemological view among medical students. This standpoint was later confirmed in various domains, e.g. engineering (Heiskanen \& Lonka, 2012).

Now the very context of higher education is radically changing. Team work and collaboration are emphasized as new $21^{\text {st }}$ century skills. The societal and cultural changes are also infiltrating the practices in higher education organisations and different learning organisations. The signifiers of academic work and strategic academic space are also in migration on a large scale (Krejsler, 2006; Pinder et al., 2009). For instance, the introduction of MOOCs (massive open online courses) now challenges many century-old practices of the universities. Epistemic agency (Scardamalia, 2002) indicates that the students deal with problems of goals, motivation, evaluation, and long-range planning that are normally left to teachers or managers. They take charge of their collaborative knowledge advancement by using new technologies, interact with communities external to the university, and bring about a real-world change. Students should themselves collaborate among themselves and plan as well as pursue for activities that they find personally meaningful; this way, they experience more ownership of their own learning and take cognitive responsibility for their own inquiry and progress. Our previous research indicates that such a process is not only intellectually, but also emotionally challenging even for highly selected groups of teacher students (Litmanen et al., 2012).

Learning takes place in both formal and informal environments, locally and globally, both virtually and socially, in successive cycles of personal and collaborative learning efforts. We must develop new ways of learning that are both intellectually activating and make students enjoy going to an educational institution. It is important to make efficient use of and develop those physical environments and tools that each university has.

People entertain various theories regarding knowledge and knowing. These epistemological beliefs have been studied extensively (e.g. Lonka, Joram \& Bryson, 1996; Hofer \& Pintrich, 2002). Previous studies have also looked at the relation between learning environments (LE) and epistemological beliefs (Lindblom-Ylänne \& Lonka, 2001; Tolhurst, 2007) and the domain specificity of the beliefs (Pintrich, 2002; Buehl \& Alexander, 2005; Hofer, 2006). Both learning environments (LE) and epistemologies have been studied over the years with different foci:

- Epistemological beliefs and learning outcomes in different LEs (Tolhurst, 2007)

- Colour and light in learning and cognitive performance (Estes, 1984; Gaoua et al., 2012; Rittner \& Robbin, 2002)

- University students' perceptions of LEs and academic outcomes (Lizzio, Wilson \& Simons, 2002)

- Congruence and friction between learning and teaching (Vermunt \& Verloop, 1999; Lonka et al., 2004)

- Student expectations from university facilities (McLaughlin \& Faulkner, 2012) 
- Learning environment, epistemological beliefs and motivation (Buehl \& Alexander, 2005; Heiskanen \& Lonka, 2012; Kember, Ho \& Hong, 2010)

- Epistemologies (Lonka \& Lindblom-Ylänne, 1996; Pintrich, 2002; Hofer \& Pintrich

- (Eds.), 2002; Richardson, 2013; Schommer-Aikins, Duell \& Barker, 2002)

On the basis of previous research, we believe that the perceptions reported by chemistry students can provide us with important insights also into how higher educational facilities and curricula could better be organized to support the new generation of learners and emerging knowledge practices.

In our previous studies, we found different epistemological profiles among different student populations. Some engineering students wanted practical, certain and factual knowledge, whereas the others were interested in reflection and collaboration (Heiskanen \& Lonka, 2012). Similar profiles were found among teacher students; these studies indicated that students' epistemological beliefs may colour the ways their learning experience in such an environment (Litmanen et al., 2012).

In this study, we assumed theoretically that laboratory tools and the environment provided external conceptual artifacts and affordances for supporting chemistry student cognition (Gibson, 1977; Hakkarainen et al., 2004; Lonka, 2009; Norman, 1993). We also assumed variation in terms of how such tools and artifacts were seen by students. Although the epistemologies found preliminarily for the future chemists seem to belong to a certain cluster, there still seems to be rich variations to how they individually experience their LE and the affordances and knowledge practices. 


\section{Problem Statement}

The study aims at defining key experiences of university chemistry students in a specialised learning environment in the context of a wet laboratory study period in organic chemistry. Gaining data on different user profiles in terms of how people entertaining different epistemologies, i.e. beliefs about knowledge, perceive their learning environment calls for new ways of combining different research methods.

\section{Research Questions}

This study is part of a larger, national interdisciplinary research programme (RYM Indoor Environment; see e.g. Heiskanen \% Lonka, 2012; Sandström et al., 2013; Sandström et al., 2014) whose main tenet is to improve and develop existing and future indoor environments and learning spaces by a combination of data and insights from a variety of different fields of expertise. In this study, we addressed the students' perceptions of the chemistry LE by the following research questions:

-What aspects of the learning environment either promoted or hindered learning?

- How did the students use technological tools in different study activities?

- How did the students experience the physical space?

\section{Purpose of the Study}

We wanted to know whether there was a relationship between student perceptions of the physical learning environment and its affordances. The overall purpose was to deepen our understanding of student perceptions of the dimensions of their LE and to develop tools to capture those experiences. We conclude the findings by a brief exploratory pre-discussion on the relationship between students' reported perception of their LE and their epistemological profile.

\section{Research Methods}

Sample

The studied chemistry student group consisted of 11 first-year students who were working on their laboratory experiments in organic chemistry. In the final sample, 9 were chosen for the pre-study between interviews and epistemological profiles.

\section{Methods}

Before the collection of data for this study, the students filled in an informed consent form giving permission to use the interview and questionnaire material for research purposes. These included the observations, interviews and the questionnaire including questions about situational academic emotions and interest and epistemological beliefs.

In this study, we delimit our focus on student reports on the learning environment and the affordances including cues from the social and the physical learning environment and the tools they used to facilitate and scaffold their actual laboratory experiments and other learning-related activities. The students were interviewed contextually in the middle of laboratory work to ensure that the chemistry domain would be active in their minds. 
The interviews were done in focus groups, and they were semi-structured including thematic questions regarding

- aspects of the learning environment that either hinder or facilitate learning;

- technological and instrumental tools (affordances) they used in their studies; and

- experiences of physical space.

The interviews were transcribed verbatim. These transcriptions were then used to study the reports and possible overarching patterns that could be identified and labelled consistently. The initial classes were formulated in a close collaboration between three researchers, so that each researcher first formed his/her own classes which were then repeatedly discussed and refined in research meetings to reach an interrater agreement.

The student reports were analysed with a focus on conceptual content analysis and semantic analysis. In cases where proximal relations between reports on the physical environment and learning were not easily captured, also other latent linguistic elements were considered contextually (e.g., the student refers to the space using pronominal or adverbial forms such as it, that, here).

The in vivo codes - for instance, instruction, basic needs, safety - were transformed into theoretical constructs where possible (overarching patterns broader than special classes, i.e. parts of certain jargon).

The final pre-study comparison between the student reports on perceptions of the LE and was performed in a blind fashion, and the possible differences in the profiles as opposed to the reports were only revealed after an in-depth study of the interview data. 9 students (5 female, 4 male) were chosen based on the richness of report given by them.

\section{Findings}

The results showed that there is much variety in student perceptions of things and contexts that either help and support them with their learning tasks and activities or, on the contrary, matters that were reported to be counter-productive in terms of learning. The wave of analyses performed on the interview data resulted in a three-category gross classification of different dimensions that the students made reference to during the contextual interviews. Many of the informants either made direct and explicit reference to matters of safety and guidance needed from the learning environment, or then these kinds of references could be subtracted proximally and semantically, when the students were using different linguistic cues to refer to safety issues, external regulation, etc.) from their reports.

Although the interviews were performed in the middle of their laboratory experiments to have the chemistry domain activated in their mental space, many students expressed a wish to have more agile learning spaces also outside the laboratory. Many of them reported a need to have differentiated spaces also within the laboratory or in close proximity to it (spaces-within-spaces that afford different kinds of learning activities individually and collaboratively). Interestingly, although collaboration and the ability to ask both peer 
students and the assistant teachers for help and advice were experienced as very important, most of the same students stated that they have to learn the content by heart, because they would be working as chemists in organisations where they might be the only experts in their field. There seemed to be a balancing between individual, route learning and the social aspect to doing e.g. calculus together with peers.

The approaches to learning and knowledge seemed many times to be quite binary: either you study and learn - on your own mostly, but for some particular tasks such as calculus, with your peer students - or you go to a lecture just because it's a lecture or because you feel obliged. In these cases, references to learning as a core function, were many times either scarce or completely lacking. One student stated, when asked about typical spaces that they use for studying:

[...] to mass lecture halls I only go for the lecture...depending completely on how useful I find the lectures. And then I use the hallways quite often, we work on assignments in groups... I think it's or I think at least for me it's a good way to learn.

When asked about how they apply different technological tools such as laptop computers, smart phones or other devices and applications in learning activities, the same student replied:

Yeah, although I think on this course it's not that important to spend time at the computer [...] Here, the main focus is after all in just getting it over with the experiments. And filling in different paper forms.

Another student pointed out the importance of having different spaces within spaces where to go work on written assignments during the wet experiments:

[...] like when you're working on something written or are searching information there could be a more classroom-like space where you could go so that you shouldn't have to work beside the dishes $[\ldots]$

This was doubled by another student who was concerned about safety:

Yeah exactly, at times you could find yourself handling your personal belongings like pens and also the phone with your rubber gloves on.

The need for more third places that induce learning was also present in many student reports. The hallways were used for learning activities, but they weren't perceived as sufficient or structured or calm enough. Here, too, the fit between peer support and individual work became obvious.

I've thought quite a lot about the entrance hall to the Department of Chemistry, that it would be nice to sit there but it's quite like...quite noisy [...] that they should be a bit more intimate so that you could be alone but at the same time connected to the hall and the surrounding environment, so that it wouldn't be a lecture hall or a library. 
The students seemed to feel that as long as collaboration doesn't affect one's own learning, it is useful to work together. A type of functional fixation or lack of productive transfer of learning could also be noticed, as seen in the following excerpt:

$[\ldots]$ in the lab, the much that you spend time there, you find out things related to the lab work and things related to that, but nothing like outside the laboratory, or like things that wouldn't have to do with the laboratory work.

Here, it seems that the learning and knowledge related to certain topics are very tightly kept to a minimum, and that you only study things in relation to the laboratory work that takes place at the given time, and do not expand your thinking across other areas of information regarding chemistry.

When the student reports were finally compared to their epistemological profiles, it was revealed that they all belonged to the same profile. That profile could be said to consist of collaborative but fact oriented and practical beliefs. However, there were many variations in the ways they perceived their environment and the affordances and factors in the LE that promoted learning. For example, some students reported far bigger mismatch between the amount of scaffolding they received from the environment and how much they would have needed guidance. Thus, the cluster and the interview data call for more person-oriented and individual profiling. In the present study, the individual reports were hence discussed within the overarching patterns induced from the interview data.

The overarching categories found in the data are presented in Table 1 below supported by examples from the student reports. An overview of the knowledge practices that were found based on the reports is presented in Table 2 .

Table 1. Categories and dimensions found for student experiences of their learning environment. 


\begin{tabular}{|c|c|c|}
\hline Category & Dimensions & Exemple \\
\hline $\begin{array}{l}\text { Promoting/hindering factors } \\
\text { in the LE }\end{array}$ & $\begin{array}{l}\text { Safe social learning atmosphere } \\
\text { - peer discussions } \\
\text { - asking assistant teachers }\end{array}$ & $\begin{array}{l}\text { At least for me being able to } \\
\text { confirm my own } \\
\text { assumptions and hunches }\end{array}$ \\
\hline $\begin{array}{ll}\text { learning, } & \text { collaboration, } \\
\text { studying } & \text { affordances }\end{array}$ & external tools & applying studied content \\
\hline $\begin{array}{l}\text { learning- } \\
\text { by-doing } \\
\text { (theory> }\end{array}$ & $\begin{array}{lr}\text { to ensure } & - \text { mainly laptop } \\
\text { 's } & \text { computers } \\
\text { umptions by } & \\
\text { ing after } & - \text { instruments in }\end{array}$ & $\begin{array}{l}\text { to learn. And it endapres,alsins } \\
\text { your courage and about future work } \\
\text { esteem there in the a chemist from } \\
\text { laboratory. You get more } \\
\text { confident. the first year on }\end{array}$ \\
\hline $\begin{array}{r}\text { own } \\
\text { - need } f \\
\text { am } \\
\text { of } g \\
\text { - learni } \\
\text { indi }\end{array}$ & $\begin{array}{l}\text { Teflectiphy \& socially distributhed lab, lab } \\
\text { orirtightgence and scaffolding equipment } \\
\text { punt \& kindht/misfit between required } \\
\text { uidance and provided guidance } \\
\text { ng is mostly (social and physical) } \\
\text { ividual }\end{array}$ & 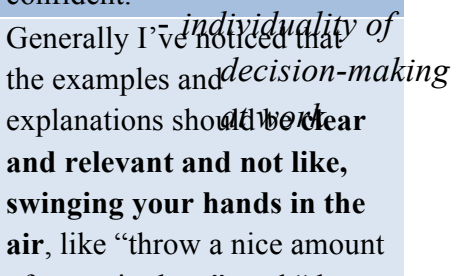 \\
\hline & & $\begin{array}{l}\text { of water in there", and "then } \\
\text { please heat it in a suitable } \\
\text { temperature for a nice amount } \\
\text { of time," } \\
\text { Like in the future, you'll } \\
\text { probably be in an Orion } \\
\text { laboratory and most probably } \\
\text { there's no-one telling you } \\
\text { "do this do this" }\end{array}$ \\
\hline \multirow[t]{2}{*}{ Safety } & Social scaffolding & $\begin{array}{l}\text { It is, though, better to ask } \\
\text { than to realize that the whole } \\
\text { place smells like bitter } \\
\text { almond [i.e., cyanide]... } \\
\text { whether we should evacuate } \\
\text { ourselves... }\end{array}$ \\
\hline & Physical scaffolding & $\begin{array}{l}\text { I think like that safety would } \\
\text { be the important thing and } \\
\text { like a clear instruction in the } \\
\text { environment, for example } \\
\text { where are the disposal } \\
\text { containers and that they } \\
\text { would be labelled well and } \\
\text { clearly }\end{array}$ \\
\hline
\end{tabular}

Table 2. Knowledge practices and approaches to knowledge and learning found in the data. 


\section{Conclusions}

We studied students that were working in a chemistry wet laboratory. In terms of LEs, a wet laboratory is a highly specialised physical environment that requires and affords for certain kinds of approaches to learning. The adjustability - or better, agility in the hands of new learners with evolving Third Millennium skills - of such spaces is often limited. In a traditional chemistry laboratory, the scaffolding artifacts such as tools for measuring different wave lengths of the molecules in a sample, or weighing chemical components on a scale, or the instructions and notes warning about dangerous liquids etc., have a certain order of being, and the user is limited by these artifacts. The potential agility (depicted below) between spaces increases as we move from laboratories to open-office type spaces that are designed to support collaborative and co-creative knowledge construction

adjustability increases

Chemistry laboratory

Traditional classroom
Multi-purpose group work room

The more traditional acquisition approach still entertained by, we believe, most educational institutions, has in recent years been challenged by a growing emphasis on how people acquire knowledge and make use of this knowledge. This participation approach takes into account how people participate in changing cultural practices and shared processes of learning (Hakkarainen et al., 2004; Hakkarainen, 2009; Harrison \& Hutton, 2014). In our view, both of these points of view into learning should be broadened and scaled up by adding in the discussion the knowledge-creation - and co-creation - approach. This approach has it that students should from early on be accustomed to regulate and immerse in individual and social efforts. This is achieved by developing shared objects of activity (Hakkarainen et al., 2004; Hakkarainen et al., 2013).

The relationship between approaches to learning and dimensions of perceived learning environment were discussed base on empirical studies already in the 1980s by Ramsden and Entwistle (1981). Lizzio, Wilson \& Simons (2002) state that changes in how the relation between different approaches to studying and learning and the LE is experienced should be also studied at the departmental level, as it is the curricular level that most often leads to changing practices in the actual course design. This implies the need to study different layers of stakeholders in any given learning organisation.

Collaborative knowledge creation should be better supported by the affordances in the LE in the broadest sense - including its physical, social and mental dimensions. For instance, Appel-Meulenbroek (2010) showed that the visibility of the co-workers and concrete copresence were experienced as innovation-promoting factors in an organisation, as the proximality enhanced e.g. the possibility to give and receive unquestioned help. It was also perceived efficient and to-the-point, as the collaborators didn't have to explain and repeat 
their point in the co-presence of others. This co-presence can and should be supported by both the facilities themselves and embedded virtual co-creation platforms.

The relation between what the space is supposed to scaffold and what it actually scaffolds (based on in-depth observational data on the space-to-person $\uparrow$ vs. person-to-space $\downarrow$ directionality) shows that space has an impact on behaviour and vice versa. In a previous preliminary study (Ketonen, Sandström \& Lonka, 2014), we found marked differences across two domains - chemistry students and teacher students in terms of their reported experiences of the learning environment and their epistemological profiles. The teacher students belonged to a profile that was labelled collaborative and reflective, whereas the chemistry students belonged in the profile labelled collaborative, fact-oriented and practical. In addition, their knowledge practices differed strongly, as the teacher students stressed the importance of practices that could be identified as knowledge co-creation, whereas the chemistry students did report collaborative preferences but at the same time, entertained ideas of fixed knowledge concerning the information that they received through their laboratory experiments.

This has been shown to be the case for medical students: too much stress and lack of emotional safety was in a study shown to make the students able to cope with the critical task at hand, but afterwards they had little if none recall of how they actually survived and which means they used to carry on with the task (LeBlanc, 2009). Perception and experience of safety in the learning environment is crucial for well-being and for such emotional state that promotes higher cognitive processes at the core of learning. This safety zone should be created and scaffolded by both the physical and the instructional, social LE (see also Mahn \& John-Steiner, 2002).

The common denominator in chemistry students' experiences regarding their LE could be found when looking more closely into the individual profiles that the students have. It could be that, although grossly in the same overarching profile, there is individual variation on different dimensions of the epistemological scale. Heiskanen \& Lonka (2012) found three different kinds of clusters based on engineering students' epistemologies and motivational strategies. Current research also debates about the domain-specific versus domain-general beliefs (see e.g. Schraw, 2013), but there is a growing tendency to state that beliefs are both domain specific and domain general. The relation between different student populations domain-wise and individual variation in perceptions of LE and epistemologies remains to be studied more extensively. However, our preliminary results have shown an interesting domain-specific variation between two academic fields (Ketonen, Sandström \& Lonka, 2014), and we plan to undertake mixed-method research designs to further see whether the differences are on the overall domain level and whether there is much variation on the individual level, as well. This will be performed by comparing the student perceptions of their LEs to their beliefs about knowledge and learning.

In the future, another dimension to be studied further is how the study context - the physical and the social - relates to the epistemological profiles. Would the same students report differently if they changed learning environments? In our present study, the epistemological cluster found to be shared by all the studied students poses interesting questions to be addressed in the future, regarding individual variation, motivational strategies and conceptions or mental models of learning. This is especially interesting to ask now that the 
methods used in education in universities are in transformation towards student-activating and student-centered methods (Lonka \& Ahola, 1995; Lonka, 2012; Loyens, Rikers \& Schmidt, 2009). This challenges the learning processes, curriculums and learning environments. Additionally, the development of technology sets new requirements for the learning landscape (Appel-Meulenbroek, 2010; Harrison \& Hutton, 2014; Pinder et al., 2009; Poutanen, Parviainen \& Åberg, 2011). In a previous study, we discussed the meaningful use of embedded learning environments in the case of teacher students who were working on an inquiry- and phenomenon-based study unit (Sandström et al., 2014). In the studied setting, the ways that different emerging applications and technologies afforded learning for the students in the form of for instance more efficient knowledge collaboration were found essential. The student reports were in line with what we nowadays think of as physically distributed cognition (Hakkarainen et al., 2013), as the students were combining different technology-supported ways of collaboration with $\mathrm{P} 2 \mathrm{P}$ discussions and intensive group work.

The relationship between different learning environments, institutional and pedagogical routines and the epistemologies that the users entertain should in the future be investigated more exhaustively - not only to understand current practices better, but particularly in order to be able to improve them and develop new knowledge practices in a dynamic interplay between emerging social practices, technologies and pedagogical innovations. This could be called the constructive alignment (after Biggs, 1996, who refers with this concept to the pedagogy) of the overall learning environment with its embedded knowledge practices and agile spaces for different learners.

This study was funded by Tekes - the Finnish Funding Agency for Innovation (project 462054) and by a grant to the first author from the Finnish Cultural Foundation.

\section{References}

Appel-Meulenbroek, R. (2010). Knowledge sharing through co-presence: added value of facilities. Facilities 28(3/4), 189-205.

Biggs, J.B. (1996). Enhancing teaching through constructive alignment. Higher Education 32(3), 347-364.

Bruner, J. (1996). The Culture of Education. Cambridge: Harvard University Press.

Buehl, M. \& Alexander, P.A. (2005) Motivation and Performance Differences in Students' DomainSpecific Epistemological Belief Profiles. American Educational Research Journal 42(4), 697-726.

Estes, R.C. (1984). Quality lighting for the learning environment. School Business Affairs 50(1), 44-45.

Gaoua, N., Granthama J., Racinais, S. \& El Massioui, F. (2012) Sensory displeasure reduces complex cognitive performance in the heat. Journal of Environmental Psychology 32, 158-163.

Gibson, J. J. (1977). The theory of affordances. In Shaw, R. \& Bransford, J. (Eds.), Perceiving, acting, and knowing: Toward an ecological psychology. Hillsdale, NJ: Erlbaum, 67-82.

Hakkarainen, K. (2009). A knowledge-practice perspective on technology-mediated learning. ComputerSupported Collaborative Learning 4, 213-231.

Hakkarainen, K., Palonen, T., Paavola, S. \& Lehtinen, E. (2004). Communities of Networked Expertise. Professional and Educational Perspectives. Earli Advances in Learning and Instruction Series. Amsterdam: Elsevier. 
Hakkarainen, K. P., Wires, S., Keskinen, J., Paavola, S., Pohjola, P., Lonka, K. \& Pyhältö, K. (2014). On personal and collective dimensions of agency in doctoral training: medicine and natural science programs. Studies in Continuing Education 36(1), 83-100.

Harrison, A. \& Hutton, L. (2014). Design for the Changing Educational Landscape. Space, place and the future of learning. Routledge.

Heiskanen, H. \& Lonka, K. (2012). Are Epistemological Beliefs and Motivational Strategies Related to Study Engagement in Higher Education? Procedia - Social and Behavioral Sciences 69, 306-313.

Kember, D., Ho, A. \& Hong, C. (2010). Characterising a teaching and learning environment capable of motivating student learning. Learning Environments Research 13, 43-57.

Ketonen, E., Sandström, N. \& Lonka, K. (2014). University students' epistemologies - how are they related to mental models of learning? Refereed conference presentation at the Earli SIG 4 \& SIG 17 joint yearly meeting at KU Leuven, Leuven, Belgium, 20.8.2014.

Krejsler, J. (2006). Discursive Battles about the Meaning of University: the case of the Danish university reform and its academics. European Educational Research Journal 5 (3/4), 210-220.

Latour, B. \& Woolgar, S. (1979). Laboratory Life. The Construction of Scientific Facts. New Jersey: Princeton University Press.

Lave, J. \& Wenger, E. (1991). Situated Learning. Legitimate peripheral participation, Cambridge: University of Cambridge Press.

LeBlanc, V.R. (2009). The Effects of Acute Stress on Performance: Implications for Health Professions Education. Academic Medicine 84(10), 25-33.

Lindblom-Ylänne, S. \& Lonka, K. (1999). Individual ways of interacting with the learning environment - are they related to study success? Learning and Instruction 9, 1-18.

Lindblom-Ylänne, S. \& Lonka, K. (2001). Students' perceptions of assessment practices in a traditional medical curriculum. Advances in Health Science Education 6, 121-140.

Litmanen, T., Lonka, K., Inkinen, M., Lipponen, L. \& Hakkarainen, K. (2012). Capturing teacher students' emotional experiences in context: Does inquiry-based learning make a difference? Instructional Science 40(6), 1083-1101.

Lizzio, A., Wilson, K. \& Simons, R. (2002). University Students' Perceptions of the Learning Environment and Academic Outcomes: implications for theory and practice. Studies in Higher Education 27(1), 27-52.

Lonka, K. (2009). Smart doctors and the three metaphors of learning. Medical Education 43(8), 718-720.

Lonka, K. (2012). Engaging Learning Environments for the Future: The 2012 Elizabeth W. Stone Lecture. In Gwyer, R., Stubbings, R. \& Walton, G. (Eds.), The road to information literacy: Librarians as facilitators of learning: IFLA Publications Series 157. Berlin/Munich: De Gruyter Saur, 15-30.

Lonka, K., Joram, E., \& Bryson, M. (1996). Conceptions of learning and knowledge - does training make a difference? Contemporary Educational Psychology 21, 240-260.

Lonka, K. \& Lindblom-Ylänne, S. (1996). Epistemologies, conceptions of learning, and study practices in medicine and psychology. Higher Education 31 (1), 5-24.

Loyens, S. M. M., Rikers, R. M. J. P., \& Schmidt, H. G. (2009). Students' conceptions of constructivist learning in different programme years and different learning environments. British Journal of Educational Psychology 79(3), 501-514.

Mahn, H. \& John-Steiner, V. (2002). The gift of confidence: A Vygotskian view of emotions. In Wells, G. \& Claxton, G. (Eds.), Learning for life in the 21st Century. Sociocultural perspectives on the future of education. Cambridge, MA: Blackwell, 47-58.

McLaughlin, P. \& Faulkner, J. (2012). Flexible spaces...what students expect from university facilities. Journal of Facilities Management 10(2), 140-149.

Norman, D.A. (1993). Things That Make Us Smart. Defending human attributes in the age of the machine. Cambridge, Massachusetts: Perseus Books. 
Pinder, J., Parkin, J., Austin, S., Duggan, F., Lansdale, M., Demian, P., Baguley, T. \& Allenby, S. (2009). The case for new academic workspaces. Loughborough (UK): Loughborough University.

Pintrich, P. R. (2002). Future challenges and directions for theory and research on personal epistemology. In B. K. Hofer, B.K. \& Pintrich, P.R (Eds.), Personal epistemology: The psychology of beliefs about knowledge and knowing. Mahwah, NJ: Erlbaum, 389-414.

Poutanen, P., Parviainen, O. \& Åberg, L. (2011). Conditions for self-organizing and creativity in blended learning environments. On The Horizon 19 (4), 286-296.

Ramsden, P.\& Entwistle, N.J. (1981) Effects of academic departments on students' approaches to studying. British Journal of Educational Psychology 51, 368-383.

Richardson, J.T.E. (2013). Epistemological development in higher education. Educational Research Review 9, 191-206.

Rittner, H., \& Robbin, M. (2002). Color and light in learning. School Planning \& Management 41(2), 5758.

Sandström, N., Sjöblom, K., Mälkki, K. \& Lonka, K. (2013). The role of physical, social and mental space in chemistry students' learning. The European Journal of Social \& Behavioural Sciences 6, 11341139.

Sandström, N., Ketonen, E. \& Lonka, K. (2014). How do university students' epistemologies guide their perceptions of the learning environment? - Triangulating latent profile analyses with interviews. Refereed conference presentation at the Earli SIG 4 \& SIG 17 joint yearly meeting at KU Leuven, Leuven, Belgium, 20.8.2014.

Sandström, N., Eriksson, R., Lonka, K. \& Nenonen, S. (2014). Usable and Affording Physical and Virtual Learning Environments. In Jensen, P.A. (Ed.), Cib Facilities Management Conference. Using Facilities in an Open World - Creating Value for All Stakeholders. 21-23 May, Copenhagen, Denmark.

Scardamalia, M. (2002). Collective cognitive responsibility for the advancement of knowledge. In B. Smith (Ed.), Liberal Education in a Knowledge Society. Chicago: Open Court, 67-98.

Schommer-Aikins, M. \& Walker, K. (1995). Are epistemological beliefs similar across domains? Journal of Educational Psychology 87, 424-432.

Schommer-Aikins, M., Duell, O.K. \& Barker, S. (2002). Epistemological Beliefs across Domains Using Biglan's Classification of Academic Disciplines. Research in Higher Education 44(3), 347-366.

Tolhurst, D. (2007). The influence of learning environments on students' epistemological beliefs and learning outcomes. Teaching in Higher Education 12(2), 219-233.

Tomasello, M. (1999). The cultural origins of human cognition. Cambridge, MA : Harvard University Press.

Vermunt, J.D. \& Verloop, N. (1999). Congruence and friction between learning and teaching. Learning and Instruction 9, 257-280.

In B. Smith (Ed.), Liberal Education in a Knowledge Society. Chicago: Open Court, pp. 67-98.

Vygotsky, L. S. (1978). Mind in society: the development of higher psychological processes. Cambridge, MA: Harvard University Press. 